\title{
The Interplay of Occupational Motivation and Well-Being During the Transition From University to Work
}

\author{
Claudia M. Haase \\ University of California, Berkeley
}

\author{
Jutta Heckhausen \\ University of California, Irvine
}

\author{
Rainer K. Silbereisen \\ University of Jena
}

\begin{abstract}
A successful entry into work is one of the key developmental tasks in young adulthood. The present 4-wave longitudinal study examined the interplay between occupational motivation (i.e., goal engagement and goal disengagement) and well-being (i.e., satisfaction with life, satisfaction with work, satisfaction with partnership, positive affect, depressive symptoms, autonomy, purpose in life, positive relations with others) during the transition from university to work. The sample consisted of 498 university graduates from 4 majors with favorable or unfavorable employment opportunities. Data were analyzed using latent growth curve modeling. The results showed that increases in goal engagement were associated with increases in numerous aspects of well-being. Increases in goal disengagement were associated with decreases in numerous aspects of well-being. However, this dynamic was not without exception. Goal engagement at graduation was associated with a decrease in autonomy and, for individuals with unfavorable employment opportunities, an increase in depressive symptoms. Goal disengagement at graduation was associated with an increase in satisfaction with work. These findings elucidate why some individuals may opt for overall maladaptive motivational strategies during the transition into the workforce: They provide selective well-being benefits. In sum, how young adults deal with their occupational goals is closely linked to changes in their well-being.
\end{abstract}

Keywords: motivation, goal engagement, goal disengagement, well-being, life-span transitions

Supplemental materials: http://dx.doi.org/10.1037/a0026641.supp

Across the life span, individuals face challenges. A prime example of such a challenge is the transition into work, one of the key developmental tasks in young adulthood (Schoon \& Silbereisen, 2009; Shulman \& Nurmi, 2010). A successful entry into work has important long-term consequences for mental and physical health, personality development, social relationships, and career success (e.g., Roberts, Walton, Bogg, \& Caspi, 2006; Schoon \& Silbereisen, 2009; Schulenberg, Bryant, \& O’Malley, 2004; Shulman \& Nurmi, 2010). Yet, young adults face increasing difficulties

This article was published Online First December 19, 2011.

Claudia M. Haase, Institute of Personality and Social Research, University of California, Berkeley; Jutta Heckhausen, School of Social Ecology, University of California, Irvine; Rainer K. Silbereisen, Department of Developmental Psychology and Center for Applied Developmental Science, University of Jena, Jena, Germany.

Analyses presented in this article are based on the dissertation by the first author, which was advised by the two coauthors and funded by the German National Academic Foundation and the Center for Applied Developmental Science, University of Jena. Work on this article was supported by German Research Foundation Grant HA 4475/2-1 to the first author. We would like to thank all study participants.

Correspondence concerning this article should be addressed to Claudia M. Haase, University of California, Berkeley, Institute of Personality and Social Research, 4143 Tolman Hall 5050, Berkeley, CA 94720-5050. E-mail: claudia.haase@berkeley.edu to enter work life and have become the "losers in a globalizing world” (Blossfeld, Klijzing, Mills, \& Kurz, 2005).

In contexts of challenge, individual agency becomes critical for positive, successful, or adaptive development (Heckhausen, Wrosch, \& Schulz, 2010). Guided by the motivational theory of lifespan development (MTD; Heckhausen et al., 2010), we sought to understand the interplay between occupational motivation (a central aspect of individual agency) and well-being (a central aspect of adaptive development) during the transition into work. Previous studies on the transition into work have yielded important insights demonstrating that young adults' agency has important consequences for their well-being, mental health, and career success (e.g., Abele, 2003; Galambos \& Krahn, 2008; Salmela-Aro, 2009; Shulman \& Nurmi, 2010). Yet, questions remain (see also Shulman \& Nurmi, 2010). Is it adaptive to pursue occupational goals tenaciously, or does such heavy investment in one life domain have costs for well-being? Is it maladaptive to adjust occupational goals to the realities at hand, or is it the key to happiness?

In the present study, we focus on university graduates, who, despite an advantaged position in the labor market, face increasing challenges in terms of finding a permanent, career-ladder job commensurate with their education (Blossfeld et al., 2005). Moreover, the graduating cohort analyzed here (graduating in Germany in the mid 2000s, sometimes coined generation internship; cf. Briedis \& Minks, 2007) earned less compared with earlier cohorts (Briedis, 2007). 


\section{Aspects of Motivation: Goal Engagement and Goal Disengagement}

Many theorists assume that individuals help shape their own development (e.g., J. J. Bauer \& McAdams, 2004; Brunstein, 1993; Deci \& Ryan, 2002; Eccles \& Wigfield, 2002; Lerner \& Busch-Rossnagel, 1981; Little, 1983; Nurmi \& Salmela-Aro, 2006; Salmela-Aro, 2009). Goals and related concepts (i.e., desired states) figure prominently in many of these approaches. In the present study, we examine how individuals deal with their goals, their occupational goals to be specific. We focus on goal engagement and goal disengagement as two basic aspects of motivation (e.g., Brandtstädter, 2009; Carver \& Scheier, 1998; Freund, Nikitin, \& Ritter, 2009; Klinger, 1975; Wrosch, Scheier, Carver, \& Schulz, 2003). Thus, to reduce discrepancies between factual states and desired states, individuals can engage with a goal and change their factual state through investing time and effort, seeking support in order to overcome obstacles, and using supporting metavolitional strategies such as enhancing control beliefs. Or they can disengage from a goal and change their desired state by withdrawing motivational commitment, lowering aspirations, and finding self-protective attributions (see Heckhausen et al., 2010). MTD posits that both goal engagement and goal disengagement have important consequences for well-being.

\section{Aspects of Well-Being: Subjective and Psychological Well-Being}

Well-being is an important aspect of successful development and has positive effects both in the short run and for long-term outcomes such as career success (e.g., Lyubomirsky, King, \& Diener, 2005). Happy individuals, for example, show better job performance and have higher incomes. Thus, the question concerning what promotes well-being has occupied laypersons and scientists alike. Researchers have increasingly directed their attention to the individual him- or herself as one source of changes in well-being across the life span (Diener, Lucas, \& Scollon, 2006). We build on this growing trend and focus on two aspects of well-being: subjective and psychological well-being. Subjective well-being refers to how individuals think and feel about their life (e.g., Diener, 2000; Kahneman, Diener, \& Schwarz, 1999) and includes aspects such as global life satisfaction, satisfaction with specific life domains, positive affect, and (inverse) negative affect. Psychological well-being refers to aspects such as autonomy, positive relations with others, and purpose in life (Ryff $\&$ Keyes, 1995). Although these two aspects of well-being are related, they are conceptually and empirically distinct (Lucas, Diener, \& Suh, 1996; Ryff \& Keyes, 1995) and thus potentially influenced differentially by different sources.

\section{Occupational Motivation and Well-Being During the Transition From University to Work}

In MTD it is assumed that how individuals deal with their goals is closely linked to their well-being. A central principle of MTD is the congruence principle (for details see Heckhausen et al., 2010). Goal engagement and goal disengagement are not per se adaptive; they are only adaptive when they are in congruence with opportunities for goal attainment. When opportunities are plentiful, goal engagement is warranted. When opportunities have vanished, goal disengagement is needed. MTD has received empirical support (for a review see Heckhausen et al., 2010) across numerous lifespan transitions including the transition into work, in different Western cultures, in different socioeconomic backgrounds, and using different study designs (e.g., longitudinal, experimental).

A successful entry into work is one of the key developmental tasks in young adulthood, where opportunities for career entry are at their peak compared with other times in the life course (Heckhausen, 2002). In this context, occupational goals are "on time" goals. Thus, occupational goal engagement should be broadly adaptive, and occupational goal disengagement should be broadly maladaptive. Engaging with occupational goals may predict wellbeing because goal engagement activates positive cognitions, produces flow experiences (Csikszentmihalyi, 2000), and promotes goal attainment (Maier \& Brunstein, 2001). Well-being, in turn, may predict occupational goal engagement (Schulz \& Heckhausen, 1998), as positive emotions serve as motivational resources (Fredrickson, 2001). Thus, over time, increases in goal engagement should go hand in hand with increases in well-being. In contrast, disengaging from occupational goals during the transition runs against age-graded opportunity structures, forecloses opportunities for long-term development, and should hence reduce wellbeing (cf. Roberts et al., 2006). Moreover, lack of well-being can motivate disengagement from goals (Wrosch \& Miller, 2009). Thus, over time, increases in goal disengagement should go hand in hand with decreases in well-being.

Longitudinal studies have shown that engaging with occupational goals indeed predicts increases, whereas disengaging predicts decreases in subjective well-being for young adults in different countries (Haase, Heckhausen, \& Köller, 2008; Messersmith \& Schulenberg, 2010; Salmela-Aro, 2009; Skaletz \& Seiffge-Krenke, 2010; Wiese, Freund, \& Baltes, 2002). These studies have provided important insights into how individual motivation predicts well-being and other outcomes of successful development. Previous research has often focused on the unidirectional effects of motivation on well-being. Yet, the interplay between motivation and well-being is likely bidirectional (Salmela-Aro, Nurmi, Saisto, \& Halmesmäki, 2001; but see Wiese et al., 2002).

Could occupational goal engagement have costs for well-being, and could goal disengagement have benefits? Various lines of research have suggested so. First, individuals who are highly engaged in a goal experience increases in not only positive emotions but also worrying (Pomerantz, Saxon, \& Oishi, 2000). Thus, high occupational goal engagement could make individuals more affectively volatile, in both positive and negative directions. Moreover, high investment in one life domain may have negative trade-offs in another life domain (Heckhausen et al., 2010). Thus, investing lots of time and energy into pursuing occupational goals may drain resources for pursuing partnership or family goals, resulting in work-family conflict (Greenhaus \& Beutell, 1985), which may, in turn, negatively impact well-being (Allen, Herst, Bruck, \& Sutton, 2000). Second, sizeable literatures have demonstrated the adaptiveness of disengaging from unattainable goals (Brandtstädter, 2009; Wrosch et al., 2003), including using selfprotective strategies such as downward social comparisons (I. Bauer \& Wrosch, 2011) or acceptance (Morling \& Evered, 2006). After all, goal disengagement reduces discrepancies between factual and desired states, which should ultimately promote well- 
being (e.g., Brandtstädter, 2009). Recent work has supported the need for further research to better understand the role of goal adjustment in young adulthood (Shulman \& Nurmi, 2010).

Finally, it is important to understand whether findings regarding the interplay between occupational motivation and well-being generalize across different contexts. Previous studies have provided important insights into how individual-level factors such as individual job attainment modulate the link between motivation and well-being (Nurmi \& Salmela-Aro, 2002; Nurmi, Salmela-Aro, \& Koivisto, 2002). In the present study, we explore generalizability across one select context-level factor that influences whether employment opportunities are scarce or plentiful during the transition from university to work - an individual's study major.

\section{The Present Study}

In the present study, we examine the interplay of occupational motivation and well-being during the transition from university to work in a four-wave longitudinal study of German university graduates. Drawing from the MTD, we hypothesized increases in occupational goal engagement to be associated with increases in well-being and increases in occupational goal disengagement to be associated with decreases in well-being. Thus, we expected correlated changes between motivation and well-being. However, we also explored the hypothesis that goal engagement may have costs and that goal disengagement may have benefits for well-being. This would translate into negative associations between goal engagement and positive associations between goal disengagement and changes in well-being. To provide an in-depth assessment of well-being benefits and costs, we studied a broad array of indicators of subjective well-being (satisfaction with life, satisfaction with work, satisfaction with partnership, positive affect, [inverse] depressive symptoms) and psychological well-being (autonomy, positive relations with others, purpose in life). Finally, we explore whether the findings generalize across four study majors associated with favorable or unfavorable employment opportunities, as determined by national graduate surveys (Briedis, 2007).

\section{Method}

\section{Participants}

We used data from a longitudinal study of 523 German university graduates from four selected majors (medicine, $n=234$; psychology, $n=79$; architecture, $n=44$; the humanities, $n=$ 166) who had graduated in 2004 or 2005 (study major was assessed at Wave 1 by a questionnaire item). In Germany, individuals can study these majors after obtaining their university entrance certificate (Abitur) after 12 or 13 years of schooling. The four majors award comparable degrees after about 5 years of study but differ markedly in postgraduation employment opportunities, as indicated by national graduate surveys (Briedis, 2007). Employment opportunities are more favorable for graduates in medicine and psychology and less favorable for graduates in architecture and the humanities. We sampled these majors to maximize heterogeneity in employment opportunities. Participants were recruited through university registration offices, press releases, and online announcements. Participation in the study was voluntary. Participants provided informed consent. Every 6 months all study par- ticipants entered a raffle for electronic gift certificates (total worth across all raffles: \$2,200). For the present study, we excluded 25 individuals with extremely low scores ( $>3 S D$ below the mean) on any of the well-being measures because outliers violate normality assumptions of structural equation modeling and because individuals with extremely low well-being may represent clinical cases, for which the MTD was not formulated. The final sample size was $498 .^{1}$

Participants in the sample were about 27 years old at graduation (medicine: $M=27.33, S D=1.93$; psychology: $M=27.95, S D=$ 4.36; architecture: $M=27.68, S D=2.63$; humanities: $M=26.47$, $S D=2.77$ ). The sample consisted of $59.6 \%$ women in medicine; $78.4 \%$ women in psychology; $57.5 \%$ women in architecture; and $84.3 \%$ women in the humanities. Mean grade point average (GPA; $1.0=$ excellent $4.0=$ poor ) was 2.24 in medicine, 1.47 in psychology, 1.75 in architecture, and 1.78 in the humanities. Analyses of participants' employment situation 1 year after graduation provided support for selecting the four majors as associated with favorable (i.e., medicine, psychology) and unfavorable (architecture, humanities) employment opportunities. Unemployment rates were lower for graduates in medicine $(2.1 \%)$ and psychology $(3.8 \%)$ than for graduates in architecture $(18.5 \%)$ and the humanities (13.3\%). Graduates in medicine (93.2\%) and psychology (94.3\%) were more likely to be gainfully employed than graduates in architecture (79.3\%) and the humanities (77.7\%). Fewer graduates in medicine $(20.3 \%)$ and psychology $(22.6 \%)$ indicated they were currently searching for a job compared with graduates in architecture $(32.1 \%)$ and the humanities (40\%). Finally, graduates in medicine $(M=7.80, S D=2.02)$ and psychology $(M=7.61$, $S D=1.83)$ indicated higher progress toward their occupational goals than did graduates in architecture $(M=6.93, S D=2.46)$ and the humanities $(M=6.63, S D=2.48)$. These differences between graduates from majors with favorable versus unfavorable employment opportunities were all significant $(p s<.01)$. In terms of participants' family and partnership situation 1 year after graduation, about $75 \%$ had a partner (medicine: $79.2 \%$; psychology: 89.1\%; architecture: $67.9 \%$; humanities: $66.1 \%$ ). About $87 \%$ were childless (medicine: $88.5 \%$; psychology: $76.8 \%$; architecture: 88.9\%; humanities: $92.2 \%$ ). The highest parental education level (attained by either mother or father) was about 12 years (medicine: $M=12.26, S D=1.52$; psychology: $M=11.72, S D=1.79$; architecture: $M=11.76, S D=1.93$; humanities: $M=11.97$, $S D=1.62$ ).

The present study used a convenience sample of university graduates. Yet, we were able to compare key sociodemographic characteristics of our study participants (as just presented) with population characteristics drawing from census data and national graduate surveys (e.g., Briedis, 2007). Comparisons were conducted separately for each major (for details see Haase, 2007). Overall, no large differences were found between study partici-

\footnotetext{
${ }^{1}$ When repeating the analyses including outliers $(N=523)$, all longitudinal associations remained essentially stable with one exception. The association between the intercept of goal disengagement and the slopes of work satisfaction $(r=.19, p=.073$ ) was reduced to trend level (because there was no significant slope variance in work satisfaction, $p=.893$, for outliers). Latent growth curve models for partnership satisfaction showed poor fit for outliers and were not analyzed.
} 
pants and the population of graduates in each major regarding the number of women (i.e., higher proportion of women in psychology and the humanities than in medicine and architecture) and GPA (i.e., highest GPA in psychology). The distribution of unemployment rates was also similar (i.e., lower unemployment rates in psychology and medicine than in architecture and the humanities); yet, unemployment rates for graduates in architecture and the humanities were higher in our sample than in the population. Moreover, across the four majors, participants in the sample were younger than graduates in the population. This difference was expected because the study targeted graduates for whom it was the first transition into work and not nontraditional students.

\section{Measures}

Motivation. Occupational goal engagement was measured by a 13-item composite scale of selective primary control striving (e.g., "I work hard to have a good occupational future"; five items), compensatory primary control striving (e.g., "If my occupational future is in danger, I will seek help [e.g., from acquaintances, friends, parents]"; four items), and selective secondary control striving (e.g., "When I think about my occupational future I often tell myself that I will surely be successful"; four items) assessed by the Optimization in Primary and Secondary Control (OPS) scales (Heckhausen, Schulz, \& Wrosch, 1998) adapted to the occupational domain and assessed on a 5-point scale ranging from 1 (strongly disagree) to 5 (strongly agree; $\alpha=.84-.85$ across Waves 1-4). These scales have demonstrated good reliability and validity (e.g., Haase et al., 2008; Tomasik, Hardy, Haase, \& Heckhausen, 2009).

Occupational goal disengagement was measured by the compensatory secondary control striving scale from the OPS scales (see earlier), which has four items (e.g., "If I cannot realize my occupational plans, I will simply settle for the next best job") measured on a 5-point scale ranging from 1 (strongly disagree) to 5 (strongly agree; $\alpha=.54-.64$ across Waves 1-4). Previous studies have repeatedly reported low internal consistencies for the goal disengagement scale (e.g., Hall, Chipperfield, Heckhausen, \& Perry, 2010; Heckhausen, Wrosch, \& Fleeson, 2001), presumably because the disengagement strategies assessed are diverse and may serve as substitutes for each other. We decided to accept low internal consistency of the goal disengagement scale based on the following considerations. First, the scale showed high validity (for details see Haase, 2007). For example, individuals who reported higher occupational goal disengagement were also more willing to accept a job for which they were overqualified $(p<.05)$. Second, the scale showed satisfactory test-retest reliabilities (i.e., intercorrelations from wave to wave ranged between .69 and .72). Third, the scale showed satisfactory reliabilities when applying the Spearman-Brown formula doubling the number of items $(\alpha=$ $.70-.78$ across Waves $1-4)$.

Well-being. Five aspects of subjective well-being were assessed. Satisfaction with life was measured by the Satisfaction With Life Scale (Diener, Emmons, Larsen, \& Griffin, 1985), which assesses global cognitive evaluations of one's life (e.g., "I am satisfied with my life") on a 7-point scale ranging from 1 (strongly disagree) to 7 (strongly agree) using five items $(\alpha=$ .82-.86 across Waves 1-4). Satisfaction with work (i.e., "How satisfied are you with your current work situation?") and satisfac- tion with partnership (i.e., "How satisfied are you with your current partnership/family situation?") were measured by one item each on a 5-point scale ranging from 1 (very dissatisfied) to 5 (very satisfied). These items pertained to global, broad evaluations of one's work and partnership situation. We used single-item measures of domain-specific satisfaction building on findings supporting their validity and reliability (e.g., Wanous, Reichers, \& Hudy, 1997).

Positive affect was measured by two items (e.g., "I was happy"; $\alpha=.64-.75$ across Waves 1-4) from the Center for Epidemiological Studies Short Depression Scale (CES-D 10; Andresen, Malmgren, Carter, \& Patrick, 1994). While the CES-D 10 was designed to assess depressive symptoms, these two items load on a different factor and have been used as measures of positive affect in numerous studies (e.g., Moskowitz, Epel, \& Acree, 2008; Pressman \& Cohen, 2005). Depressive symptoms were measured by the remaining eight items from the CES-D 10 (e.g., "I felt depressed," "I felt fearful"; $\alpha=.75-.83$ across Waves $1-4)$. The CES-D 10 assesses affective states experienced during the last week on a 4-point scale ranging from 1 (rarely, less than one day) to 4 (all of the time, 5-7 days). We note that aspects of negative affect including depressive symptoms are indicators of ill-being rather than well-being, but in line with the literature (e.g., Diener, 2000), we subsumed (inverse) depressive symptoms under the common header of well-being.

Three aspects of psychological well-being were measured using items from the Psychological Well-Being scales (Ryff \& Keyes, 1995) that measured autonomy (e.g., "I am not afraid to voice my opinions, even when they are in opposition to the opinions of most people"; $\alpha=.76-.83$ across Waves $1-4)$, positive relations with others (e.g., "I know that I can trust my friends, and they know they can trust me"; $\alpha=.79-.85$ across Waves $1-4)$, and purpose in life (e.g., "Some people wander aimlessly through life, but I am not one of them"; $\alpha=.74-.81$ across Waves $1-4)$. Nine items from each measure were rated on a 6-point scale ranging from 1 (strongly disagree) to 6 (strongly agree).

\section{Procedure and Design}

Data were collected at graduation (Wave 1) and at 4 months (Wave 2), 8 months (Wave 3), and 12 months (Wave 4) after graduation. At all waves, all measures were assessed except for satisfaction with partnership, which was assessed for a subsample $(n=171)$ at Wave 1 and for all available participants at all other waves. Forty-four percent participated in all four waves, $24.9 \%$ participated in three waves, $19.9 \%$ participated in two waves, and $11.0 \%$ participated in one wave of data collection. It was possible for participants to not take part in one wave and reenter the study at a later wave. Correlations between participation depth (i.e., number of waves an individual took part in) and all study variables and sociodemographic characteristics (i.e., gender, age, GPA, parental education) were nonsignificant ( $p s>.05$ ), indicating that participation depth was nonselective.

Data were collected online. Studies have shown that "data provided by Internet methods are of at least as good quality as those provided by traditional paper-and-pencil methods" (Gosling, Vazire, Srivastava, \& John, 2004, p. 102). To secure high-quality data collection, various measures were implemented following recommendations by Nosek, Banaji, and Greenwald (2002). Par- 
ticipants could access the questionnaires only by using a confidential password, which they received by e-mail. Moreover, we secured adequate information and debriefing (i.e., information on the study website including frequently asked questions, information e-mails, debriefing at the end of the study, opportunities to contact the first author); ensured adequate anonymity and security (i.e., secure password access, anonymous data collection, separate storage of contact information and questionnaire files); and sought to minimize dropout by sending thank-you e-mails and reminders, conducting telephone follow-ups, and offering incentives (i.e., gift certificates).

\section{Statistical Analyses}

We used latent growth curve modeling within a structural equation modeling framework (e.g., Duncan \& Duncan, 2004; McArdle \& Epstein, 1987) using Mplus 5 (Muthén \& Muthén, 1998-2007). In latent growth curve modeling, two latent variables are modeled: the intercept and the slope. In the present study, the intercept mean indicated the average latent mean of the construct at Wave 1. A significant intercept variance indicated that individuals differed around this mean. The slope mean indicated the average latent change in the construct over time. A significant slope variance indicated that individuals differed in intraindividual change in the construct over time.

As indicators of model fit, we inspected chi-square, the Comparative Fit Index (CFI), the Tucker-Lewis Index (TLI), and the root mean square error of approximation (RMSEA). For the TLI and CFI, we used a cutoff value of .95 as a guideline. For the RMSEA, we followed Browne and Cudeck (1993), who recommend RMSEA $<.08$ as an indicator of reasonable fit (cf. Marsh, Hau, \& Wen, 2004).

Our analyses proceeded in two steps. In the first step, we conducted preliminary analyses examining descriptive statistics, measurement models, measurement equivalence, and univariate latent growth curve models (LGMs). To examine measurement models, we conducted confirmatory factor analyses using structural equation modeling. To examine measurement equivalence, we tested factorial equivalence over time using structural equation modeling (Byrne \& Stewart, 2006). For each construct, we compared an unconstrained measurement model with free factor loadings to a measurement model where factor loadings were constrained to be equal across time. Factorial equivalence held when the unconstrained model did not fit better than did the constrained model $\left(\Delta \chi^{2}, p>.05\right)$. To examine univariate latent growth curve modeling for each construct, we started with a linear LGM (e.g., Coffman \& Millsap, 2006) with intercept loadings of $[1 ; 1 ; 1 ; 1]$ and slope loadings of $[0 ; 1 ; 2 ; 3]$. We moved on to a nonlinear LGM with freely estimated slope loadings at two waves when the nonlinear model showed better fit than did the linear model $\left(\Delta \chi^{2}\right.$, $p<.10$ ). Intercept and slope were allowed to correlate. Residual variances were constrained to be equal across waves with one exception as indicated later. In a few cases, we constrained a nonsignificant or negatively estimated residual variance of a manifest variable to zero as recommended by Hox (2002).

In the second step, we examined a series of bivariate LGMs for motivation and well-being to test our hypotheses. Specifically, we modeled a univariate LGM for an aspect of motivation and a univariate LGM for an aspect of well-being and examined the bivariate correlations between intercepts and slopes (e.g., Duncan \& Duncan, 2004). A significant intercept-intercept correlation indicated that motivation and well-being were correlated at graduation. A significant lagged correlation between the motivation intercept and the well-being slope indicated that motivation at graduation was associated with change in well-being over time. A significant lagged correlation between the well-being intercept and the motivation slope indicated that well-being at graduation was associated with change in motivation over time. A significant slope-slope correlation indicated that change in motivation was associated with change in well-being. Note that the interpretation of a slope correlation is unaffected by the slope mean. That is, a positive slope-slope correlation indicates that increases in one construct are associated with increases in the other construct, regardless of the average mean-level change in these constructs.

Prior to inspecting the bivariate LGMs, we examined whether the longitudinal associations generalized across employment opportunities using multigroup modeling (e.g., Duncan \& Duncan, 2004) comparing the group of graduates with favorable employment opportunities (i.e., medicine, psychology; $n=301$ ) with the group of graduates with unfavorable employment opportunities (i.e., architecture, humanities; $n=197$ ). Following the work of others (e.g., Byrne \& Stewart, 2006), we tested for moderation by comparing an unconstrained model and a model where the relevant longitudinal associations (i.e., intercept-slope and slope-slope correlations) were constrained to be equal. A nonsignificant chisquare difference test indicated that associations generalized across employment opportunities.

All participants were included in the analyses. Missing data were estimated using Mplus's full-information maximum likelihood algorithm.

\section{Results}

\section{Preliminary Analyses}

Descriptive statistics. Table 1 shows the within-wave intercorrelations for all variables at Waves $1-4$. Small negative correlations were found between goal engagement and goal disengagement. Correlations between aspects of subjective and psychological well-being ranged from nonsignificant (e.g., satisfaction with work and autonomy) to high (e.g., satisfaction with life and purpose in life) but were not exceedingly high. Table 2 shows estimated means and standard deviations for all variables (based on mean scores) at Waves 1-4. Univariate latent growth curve modeling (see Table 3) was used to analyze which of the mean-level changes shown in Table 2 were significant. All variables were normally distributed at all waves (skewness $\leq 1.23$; kurtosis $\leq 1.13$ ). In Tables 1 and 2 , we present data for the whole sample. Data broken down by employment opportunities are available in the online supplemental materials (see Tables S1, S2, and S3).

Measurement models and measurement equivalence. We examined measurement models and measurement equivalence for each construct in the sample. Due to space constraints, these analyses are briefly summarized here (for detailed information see Haase, 2007). The measurement models showed adequate model fit for all constructs at each wave according to the fit criteria defined earlier. Moreover, factorial equivalence across time was 
Table 1

Intercorrelations for All Study Variables at Waves 1-4

\begin{tabular}{|c|c|c|c|c|c|c|c|c|c|c|}
\hline Aspect & 1 & 2 & 3 & 4 & 5 & 6 & 7 & 8 & 9 & 10 \\
\hline \multirow[t]{2}{*}{ 1. GE } & - & $3:-.11^{*}$ & $3: .25^{* * * * *}$ & $3: .23^{* * * *}$ & $3: .19^{* * * * *}$ & 3: $.11^{*}$ & $3:-.06$ & 3: $.12^{*}$ & $3: .15^{* * *}$ & 3: $.45^{* * * * *}$ \\
\hline & & $4:-.17^{* * *}$ & $4: .26^{* * * *}$ & $4: .23^{* * * *}$ & 4: .09 & $4: .28^{* * * *}$ & $4:-.13^{*}$ & 4: $.11^{*}$ & $4: .22^{* * * *}$ & 4: $.47^{* * * * *}$ \\
\hline \multirow{2}{*}{ 2. GD } & $1:-.14^{* *}$ & - & $3:-.10$ & $3:-.16^{* *}$ & $3:-.05$ & 3: .04 & 3: .05 & $3:-.17^{* *}$ & $3:-.02$ & $3:-.26^{* * * *}$ \\
\hline & $2:-.19^{* * * *}$ & & $4:-.16^{* * *}$ & $4:-.22^{* * * *}$ & $4:-.01$ & $4:-.10$ & $4: .14^{*}$ & $4:-.15^{* *}$ & $4:-.02$ & $4:-.28^{* * * * *}$ \\
\hline \multirow[t]{2}{*}{ 3. SWL } & 1: .07 & $1:-.10$ & - & 3: $.50^{* * * *}$ & 3: $.48^{* * * *}$ & 3: $.49^{* * * *}$ & $3:-.41^{* * * *}$ & 3: .08 & 3: $.34^{* * * *}$ & $3: .50^{* * * * *}$ \\
\hline & $2: .19^{* * * *}$ & $2:-.15^{* *}$ & & $4: .56^{* * *}$ & $4: .49^{* * * *}$ & $4: .52^{* * * *}$ & $4:-.39^{* * * *}$ & 4: $.13^{*}$ & $4: .42^{* * * *}$ & $4: .49^{* * * *}$ \\
\hline \multirow[t]{2}{*}{ 4. SWW } & 1: .09 & $1:-.16^{* *}$ & 1: $.45^{* * * *}$ & - & 3: $.20^{* * * *}$ & 3: $.38^{* * * * *}$ & $3:-.26^{* * * *}$ & 3: .03 & $3: .14^{* *}$ & 3: $.33^{* * * * *}$ \\
\hline & $2: .16^{\text {*** }}$ & $2:-.26^{* * * *}$ & $2: .51^{* * * *}$ & & $4: .16^{* *}$ & $4: .38^{* * * *}$ & $4:-.27^{* * * *}$ & $4: .15^{* *}$ & 4: $.21^{* * * *}$ & $4: .38^{* * * *}$ \\
\hline \multirow[t]{2}{*}{ 5. SWP } & 1: .06 & 1: .04 & $1: .54^{* * * *}$ & 1: .10 & - & $3: .23^{* * * *}$ & $3:-.25^{* * * *}$ & 3: .01 & 3: $.27^{* * * *}$ & 3: $.29^{* * * * *}$ \\
\hline & 2: .07 & 2: .04 & $2: .47^{* * * *}$ & 2: .11* & & $4: .27^{* * * *}$ & $4:-.32^{* * *}$ & $4:-.01$ & 4: $.27^{* * * *}$ & $4: .24^{* * * * *}$ \\
\hline \multirow[t]{2}{*}{ 6. PA } & 1: .09 & $1:-.15^{* * *}$ & $1: .54^{* * * *}$ & $1: .39^{* * * *}$ & $1: .36^{* * * * *}$ & - & $3:-.52^{* * * *}$ & 3:. .08 & 3: $.33^{* * * * *}$ & $3: .33^{\text {**** }}$ \\
\hline & $2: .18^{* * * * *}$ & $2:-.12^{*}$ & $2: .56^{* * * *}$ & $2: .44^{* * * *}$ & $2: .21^{* * * * *}$ & & $4:-.46^{* * * *}$ & $4: .12^{*}$ & $4: .33^{* * * * *}$ & $4: 46^{\text {***** }}$ \\
\hline \multirow[t]{2}{*}{ 7. DEP } & $1:-.01$ & $1: .13^{*}$ & $1:-.39^{* * * *}$ & $1:-.26^{* * * *}$ & $1:-.39^{* * * *}$ & $1:-.56^{* * * *}$ & - & $3:-.20^{* * * *}$ & $3:-.29^{* * * *}$ & $3:-.35^{\text {**** }}$ \\
\hline & $2:-.09$ & $2: .12^{*}$ & $2:-.49^{* * * *}$ & $2:-.38^{* * *}$ & $2:-.20^{* * * *}$ & $2:-.61^{* * * *}$ & & $4:-.18^{* *}$ & $4:-.27^{* * * *}$ & $4:-.37^{* * * * *}$ \\
\hline \multirow[t]{2}{*}{ 8. AUT } & 1: .01 & $1:-.15^{* * *}$ & $1: .19^{* * * *}$ & 1: .01 & 1: $.15^{*}$ & $1: .26^{* * * *}$ & $1:-.33^{* * * *}$ & - & $3: .20^{* * * *}$ & 3: $.28^{* * * * *}$ \\
\hline & $2: .03$ & $2:-.07$ & $2: .13^{*}$ & $2:-.02$ & 2: .03 & $2: .14^{* * *}$ & $2:-.23^{* * * *}$ & & $4: .20^{* * * *}$ & $4: .29^{* * * * *}$ \\
\hline \multirow[t]{2}{*}{ 9. POS } & $1: .10^{*}$ & $1:-.02$ & $1: .43^{* * * * *}$ & $1: .18^{* *}$ & $1: .33^{* * * *}$ & $1: .38^{* * * * *}$ & $1:-.29^{* * * *}$ & $1: .16^{* *}$ & - & 3: $.47^{* * * * *}$ \\
\hline & $2: .19^{* * *}$ & 2: .01 & $2: .42^{* * * *}$ & $2: .16^{* *}$ & $2: .26^{* * * *}$ & $2: .38^{* * * *}$ & $2:-.35^{* * *}$ & $2: .14^{* *}$ & & $.45^{* * * *}$ \\
\hline \multirow[t]{2}{*}{ 10. PUR } & $1: .34^{* * *}$ & $1:-.28^{* * * *}$ & $1: .43^{* * * *}$ & $1: .31^{* * * *}$ & $1: .29^{* * *}$ & $1: .41^{* * * *}$ & $1:-.32^{* * *}$ & $1: .31^{* * *}$ & $1: .43^{* * *}$ & - \\
\hline & $2: .42^{* * * *}$ & $2:-.16^{* * * *}$ & $2: .38^{* * * *}$ & $2: .26^{* * * *}$ & $2: .16^{* * *}$ & $2: .36^{* * * *}$ & $2:-.38^{* * * *}$ & $2: .15^{* *}$ & $2: .42^{* * * *}$ & \\
\hline
\end{tabular}

Note. Within-wave intercorrelations at Waves 1 and 2 are shown below the diagonal, and within-wave intercorrelations at Waves 3 and 4 appear above the diagonal. $\mathrm{GE}=$ goal engagement; GD = goal disengagement; SWL = satisfaction with life; SWW = satisfaction with work; SWP $=$ satisfaction with partnership; PA = positive affect; DEP = depressive symptoms; AUT = autonomy; POS = positive relations with others; PUR = purpose in life.

${ }^{*} p<.05 .^{* *} p<.01 .^{* * * *} p<.001$.

established for all constructs $(p s>.05)$ with the exception of positive relations with others $\left(\Delta \chi^{2}(24)=40.07, p<.05\right)$. However, measurement equivalence was not seriously threatened, as the explained variance was high for all items across all waves $\left(R^{2} \geq .85\right)$ and no systematic bias emerged. Moreover, when freeing the residual variances for positive relations with others in the bivariate LGM (see Bivariate LGMs for Occupational Goal Engagement and Well-Being section later), all results remained stable. We decided to retain this construct in the analyses.

Univariate LGMs. Table 3 presents fit indices and parameters for the final univariate LGMs. Univariate linear LGMs showed adequate model fit for goal disengagement, satisfaction with life, satisfaction with work, satisfaction with partnership, and positive

Table 2

Estimated Means (and Standard Deviations) for All Study Variables at Waves 1-4

\begin{tabular}{lcccc}
\hline Aspect & Wave 1 & Wave 2 & Wave 3 & Wave 4 \\
\hline GE & $3.78(0.53)$ & $3.75(0.52)$ & $3.66(0.54)$ & $3.75(0.52)$ \\
GD & $2.91(0.64)$ & $2.85(0.66)$ & $2.82(0.70)$ & $2.75(0.69)$ \\
SWL & $5.22(1.03)$ & $5.15(1.03)$ & $5.20(0.97)$ & $5.22(1.01)$ \\
SWW & $3.40(1.22)$ & $3.45(1.21)$ & $3.67(1.14)$ & $3.74(1.05)$ \\
SWP & $3.82(1.12)$ & $3.84(1.10)$ & $3.82(1.12)$ & $3.83(1.11)$ \\
PA & $2.93(0.77)$ & $3.04(0.77)$ & $3.06(0.72)$ & $3.05(0.75)$ \\
DEP & $1.66(0.57)$ & $1.55(0.49)$ & $1.50(0.44)$ & $1.49(0.42)$ \\
AUT & $3.96(0.64)$ & $3.82(0.66)$ & $3.96(0.67)$ & $3.99(0.65)$ \\
POS & $4.80(0.66)$ & $4.72(0.71)$ & $4.76(0.69)$ & $4.81(0.68)$ \\
PUR & $4.76(0.66)$ & $4.69(0.64)$ & $4.70(0.64)$ & $4.71(0.64)$ \\
\hline
\end{tabular}

Note. $\mathrm{GE}=$ goal engagement; GD = goal disengagement; $\mathrm{SWL}=$ satisfaction with life; SWW = satisfaction with work; SWP = satisfaction with partnership; PA = positive affect; DEP $=$ depressive symptoms; AUT $=$ autonomy; POS $=$ positive relations with others; PUR = purpose in life. affect. Univariate nonlinear LGMs were specified for the remaining constructs. The fit of all final univariate models was reasonable. All constructs showed significant slope variances. That is, individual differences in intraindividual change were present for all constructs. In addition, we explored mean-level changes indicated by the slope means. Goal engagement and goal disengagement on average decreased. Satisfaction with work and positive affect on average increased. Satisfaction with life and satisfaction with partnership on average remained stable. Depressive symptoms and purpose in life on average decreased. Due to the slope parameterization in the nonlinear LGMs with freely estimated slope loadings at Waves 3 and 4, the slope means were also negative for autonomy and positive relations with others indicating average decreases from Wave 1 to Wave 2. However, as can be seen in the manifest means (see Table 2) and the slope loadings at Waves 3 and 4 (see Table 3), autonomy and purpose in life recovered after this temporary drop and returned to initial levels.

\section{Bivariate LGMs for Occupational Goal Engagement and Well-Being}

We examined a series of bivariate LGMs for occupational goal engagement and well-being building on the univariate LGMs. Table 4 presents results for the test for moderation by employment opportunities and the model fit indices of the final bivariate LGMs. Employment opportunities moderated the longitudinal bivariate correlations between goal engagement and depressive symptoms. Note that a linear LGM was used for goal engagement to overcome a convergence problem, building on findings by Coffman and Millsap (2006), who demonstrated that linear LGMs can show poor fit even when the quadratic component is small and a linear model would be adequate. This was the case for goal engagement 
Table 3

Model Fit and Parameters of the Final Univariate LGMs

\begin{tabular}{|c|c|c|c|c|c|c|c|c|c|}
\hline \multirow[b]{2}{*}{ Aspect } & \multicolumn{4}{|c|}{ Model fit } & \multicolumn{2}{|c|}{ Intercept (I) } & \multicolumn{2}{|c|}{ Slope (S) } & \multirow[b]{2}{*}{$r(\mathrm{I}, \mathrm{S})$} \\
\hline & $\chi^{2}(d f)$ & CFI & TLI & RMSEA & $M$ & Var & $M$ & Var & \\
\hline $\mathrm{GE}^{\mathrm{a}}$ & $9.07(6)$ & 1.00 & 1.00 & .032 & $3.78^{* * * * *}$ & $.202^{* * * *}$ & $-.04^{* * * * *}$ & $.011^{*}$ & .00 \\
\hline $\mathrm{GD}^{\mathrm{b}}$ & $7.61(8)$ & 1.00 & 1.00 & .000 & $2.91^{* * * *}$ & $.294^{* * * *}$ & $-.05^{* * * *}$ & $.014^{* * * *}$ & -.13 \\
\hline $\mathrm{SWL}^{\mathrm{b}}$ & $20.87^{* * *}(8)$ & .98 & .99 & .057 & $5.19^{* * * *}$ & $.828^{* * * *}$ & .00 & $.031^{* * * * *}$ & $-.35^{\text {**** }}$ \\
\hline $\mathrm{SWW}^{\mathrm{b}}$ & $22.42^{* * *}(8)$ & .93 & .95 & .061 & $3.36^{* * * *}$ & $.914^{* * * *}$ & $.13^{\text {***** }}$ & $.085^{* * * *}$ & $-.66^{* * *}$ \\
\hline $\mathrm{SWP}^{\mathrm{b}}$ & $2.56(8)$ & 1.00 & 1.00 & .000 & $3.83^{* * * *}$ & $.871^{* * * *}$ & .00 & $.031^{*}$ & $-.31^{*}$ \\
\hline $\mathrm{PA}^{\mathrm{b}}$ & 9.77 (8) & .99 & 1.00 & .021 & $2.96^{* * * * *}$ & $.321^{* * * * *}$ & $.04^{*}$ & $.023^{* * *}$ & $-.51^{* * * * *}$ \\
\hline $\mathrm{DEP}^{\mathrm{a}}$ & $10.29(6)$ & .98 & .98 & .038 & $1.66^{* * * *}$ & $.209^{* * * * *}$ & $-.11^{\text {****** }}$ & $.037^{*}$ & $-.79^{\text {**** }}$ \\
\hline $\mathrm{AUT}^{\mathrm{a}}$ & $17.26^{* *}(6)$ & .99 & .99 & .062 & $3.97^{* * * * *}$ & $.331^{* * * *}$ & $-.15^{* * * * *}$ & $.029^{*}$ & -.10 \\
\hline $\mathrm{POS}^{\mathrm{a}}$ & $11.33(6)$ & 1.00 & 1.00 & .042 & $4.79^{* * * * *}$ & $.364^{* * * * *}$ & $-.08^{* * *}$ & $.039^{*}$ & .07 \\
\hline PUR $^{\mathrm{a}}$ & $14.43^{*}(6)$ & .99 & .99 & .053 & $4.76^{* * * *}$ & $.441^{* * * *}$ & $-.06^{* * *}$ & $.127^{* * * *}$ & $-.55^{\text {**** }}$ \\
\hline
\end{tabular}

Note. $\quad$ LGM = latent growth curve model; Var = variation; CFI = Comparative Fit Index; TLI = Tucker-Lewis Index; RMSEA = root mean square error of approximation; GE = goal engagement; GD = goal disengagement; SWL = satisfaction with life; SWW = satisfaction with work; SWP = satisfaction with partnership; PA = positive affect; DEP $=$ depressive symptoms; AUT $=$ autonomy; POS $=$ positive relations with others; PUR = purpose in life.

${ }^{\text {a }}$ Nonlinear LGMs. Slope loadings were set to [0; 1 ; free; free] for all constructs except for GE [0; free; free; 1] to enhance slope variability. Slope loadings at Waves 2-4 were for GE (Wave 2: .25, Wave 3: 2.87, Wave 4: 1), DEP (Wave 2: 1, Wave 3: 1.43, Wave 4: 1.55), AUT (Wave 2: 1, Wave 3: .00, Wave

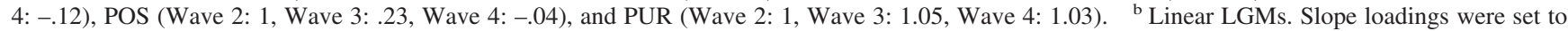
$[0 ; 1 ; 2 ; 3]$.

${ }^{*} p<.05 . * * p<.01 .{ }^{* * * *} p<.001$.

in the present study. As can be seen in Table 4, the final bivariate LGMs showed satisfactory fit.

Figure 1 presents the structural part of the bivariate LGMs and the significant bivariate correlations. Various positive interceptintercept correlations were found. Thus, goal engagement was positively associated with satisfaction with life, positive affect, positive relations with others, and purpose in life at graduation. The intercept correlation between goal engagement and depressive symptoms was positive when employment opportunities were favorable and negative when opportunities were unfavorable.

Next, the lagged correlations were analyzed. A lagged correlation was found between goal engagement and depressive symptoms, which was moderated by employment opportunities. Thus, when opportunities were favorable, goal engagement at graduation was associated with a decrease in depressive symptoms. In con- trast, when opportunities were unfavorable, goal engagement at graduation was associated with an increase in depressive symptoms. Moreover, goal engagement at graduation was associated with a decrease in autonomy. Satisfaction with partnership at graduation was associated with an increase in goal engagement.

Finally, various positive slope-slope correlations were found. Thus, increases in goal engagement were associated with increases in satisfaction with life, positive affect, positive relations with others, and purpose in life.

\section{Bivariate LGMs for Occupational Goal Disengagement and Well-Being}

We proceeded to examine a series of bivariate LGMs for occupational goal disengagement and well-being, building on the uni-

Table 4

Occupational Goal Engagement (GE) and Well-Being: Test for Moderation and Model Fit of the Final Bivariate LGMs

\begin{tabular}{|c|c|c|c|c|c|}
\hline \multirow[b]{2}{*}{ GE and well-being aspect } & \multirow[b]{2}{*}{$\begin{array}{l}\text { Moderation by employment } \\
\text { opportunities } \Delta \chi^{2}(d f)\end{array}$} & \multicolumn{4}{|c|}{ Model fit } \\
\hline & & $\chi^{2}(d f)$ & CFI & TLI & RMSEA \\
\hline GE-SWL & $2.64(3)$ & $83.30^{* * * *}(28)$ & .97 & .97 & .063 \\
\hline GE-SWW & $3.48(3)$ & $78.55^{* * *}(28)$ & .96 & .96 & .060 \\
\hline GE-SWP & $5.59(3)$ & $67.12^{* * * *}(28)$ & .97 & .97 & .053 \\
\hline GE-PA & $0.99(3)$ & $68.62^{* * *}(28)$ & .97 & .97 & .054 \\
\hline GE-DEP ${ }^{\mathrm{a}}$ & $9.00^{* * *}(3)$ & $112.46^{* * *}(48)$ & .95 & .94 & .074 \\
\hline GE-AUT & $6.18(3)$ & $75.25^{* * *}(26)$ & .97 & .97 & .062 \\
\hline GE-POS & $3.59(3)$ & $86.87^{* * *}(26)$ & .97 & .97 & .069 \\
\hline GE-PUR & $2.42(3)$ & $93.64^{* * *}(26)$ & .97 & .96 & .072 \\
\hline
\end{tabular}

Note. $\quad$ LGM = latent growth curve model; Comparative Fit Index; TLI = Tucker-Lewis Index; RMSEA = root mean square error of approximation; $\mathrm{SWL}=$ satisfaction with life; SWW = satisfaction with work; SWP = satisfaction with partnership; PA = positive affect; DEP = depressive symptoms; $\mathrm{AUT}=$ autonomy; POS $=$ positive relations with others; PUR $=$ purpose in life

${ }^{a}$ Model fit for the multigroup model (residual variances of GE freely estimated).

${ }^{* * *} p<.01$ **** $^{* *}<<.001$. 


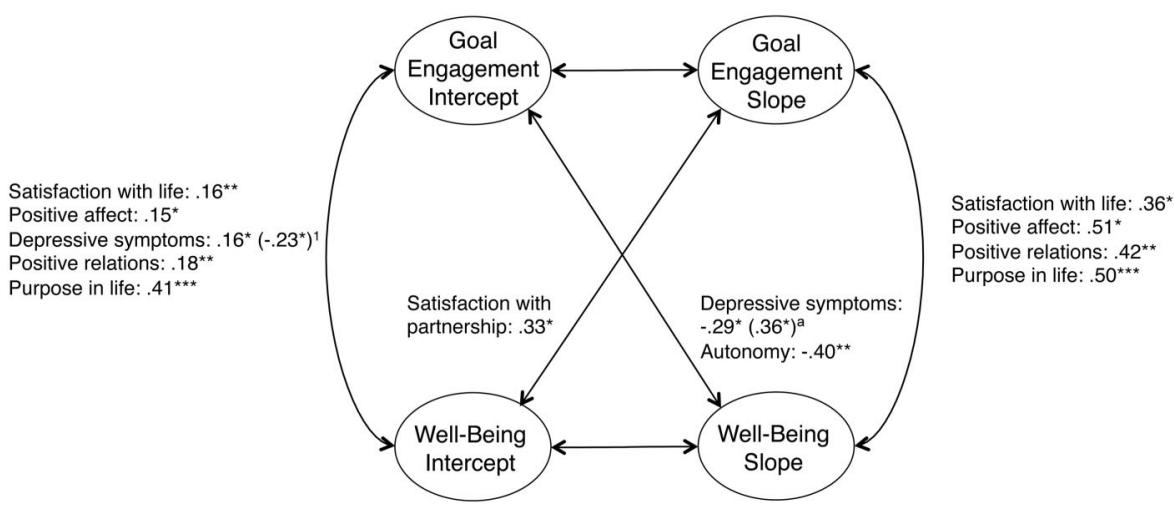

Figure 1. Occupational goal engagement and well-being: Results for six bivariate structural latent growth curve models. Significant bivariate correlations are shown $(p \mathrm{~s}<.05)$. All other bivariate correlations were nonsignificant $(p s>.05)$. ${ }^{a}$ Parameter estimates for favorable (in parentheses for unfavorable) employment opportunities. ${ }^{*} p<.05$. $^{* *} p<.01$. $^{* * *} p<.001$.

variate LGMs (a nonlinear model was specified for satisfaction with work, see later). Table 5 presents results for the test for moderation by employment opportunities and the model fit indices of the final bivariate LGMs. Employment opportunities moderated the longitudinal bivariate correlations between goal disengagement and satisfaction with life and positive affect. All final bivariate LGMs showed satisfactory fit.

Figure 2 presents the structural part of the bivariate LGMs and the significant bivariate correlations. Various negative interceptintercept correlations were found. Thus, goal disengagement was negatively associated with satisfaction with work, autonomy, and purpose in life and positively associated with depressive symptoms.

Next, the lagged correlations were analyzed. A positive lagged correlation was found between the goal disengagement intercept and the work satisfaction slope, which was significant when a nonlinear model was specified for satisfaction with work. Thus, goal disengagement at graduation was associated with an increase in satisfaction with work. Moreover, goal disengagement at grad- uation was associated with a decrease in satisfaction with partnership.

Finally, various negative slope-slope correlations were found. Thus, increases in goal disengagement were associated with decreases in positive relations with others; purpose in life; and, when employment opportunities were favorable, positive affect.

\section{Discussion}

In the present study, we examined the interplay of occupational motivation and well-being during the transition from university to work in a four-wave longitudinal study of German university graduates. We found that increases in occupational goal engagement were associated with increases in numerous aspects of wellbeing, whereas increases in occupational goal disengagement were associated with decreases in numerous aspects of well-being. However, goal engagement at graduation was associated with a decrease in autonomy and, for individuals with unfavorable employment opportunities, an increase in depressive symptoms.

Table 5

Occupational Goal Disengagement (GD) and Well-Being: Test for Moderation and Model Fit of the Final Bivariate LGMs

\begin{tabular}{ccrrr}
\hline & & & \multicolumn{2}{c}{ Model fit } \\
\cline { 3 - 5 } GD and well-being aspect & $\begin{array}{c}\text { Moderation by employment } \\
\text { opportunities } \Delta \chi^{2}(d f)\end{array}$ & CFI & TLI \\
\hline GD-SWL & $9.99^{*}(3)$ & $59.09(56)$ & 1.00 & 1.00 \\
GD-SWW & $5.92(3)$ & $41.36^{*}(26)$ & .98 & .015 \\
GD-SWP & $2.07(3)$ & $20.03(28)$ & .035 \\
GD-PA & $8.07^{*}(3)$ & $70.85(56)$ & .000 \\
GD-DEP & $3.98(3)$ & $42.64^{*}(26)$ & .00 & .98 \\
GD-AUT & $3.93(3)$ & $32.36(26)$ & .98 & .98 \\
GD-POS & $0.63(3)$ & $41.08^{*}(26)$ & 1.00 & .03 \\
GD-PUR & $4.65(3)$ & $55.96^{* * *}(26)$ & .99 & .036 \\
\hline
\end{tabular}

Note. $\quad$ LGM = latent growth curve model; Comparative Fit Index; TLI = Tucker-Lewis Index; RMSEA = root mean square of approximation; SWL = satisfaction with life; SWW = satisfaction with work; SWP = satisfaction with partnership; PA = positive affect; DEP = depressive symptoms; AUT = autonomy; POS = positive relations with others; PUR = purpose in life.

${ }^{a}$ Model fit for the multigroup model.

${ }^{*} p<.05 .{ }^{* * * *} p<.001$. 


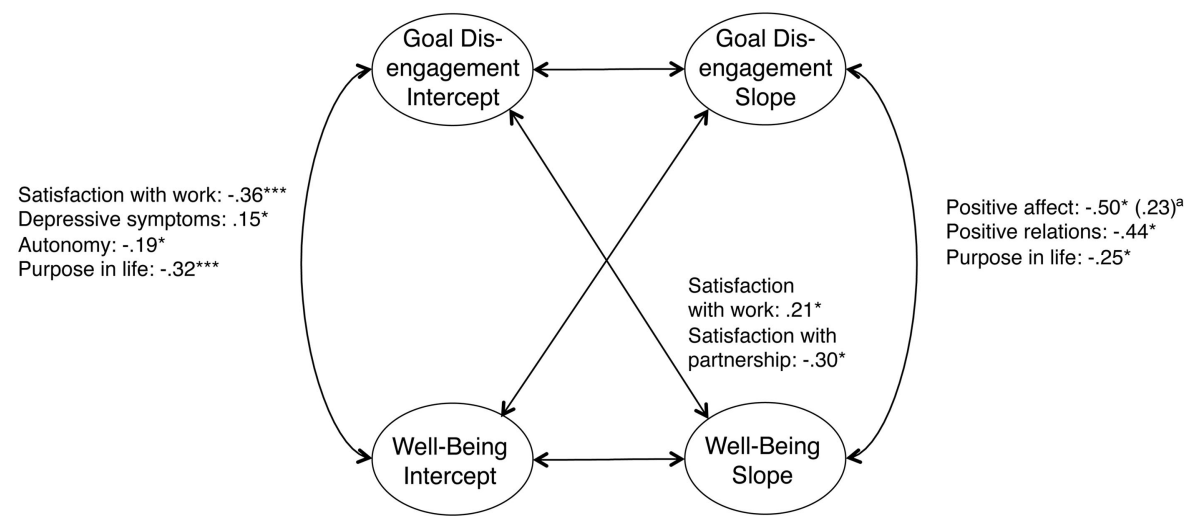

Figure 2. Occupational goal disengagement and well-being: Results for six bivariate structural latent growth curve models. Significant bivariate correlations are shown $(p s<.05)$. All other bivariate correlations were nonsignificant ( $p \mathrm{~s}>.05)$. ${ }^{\mathrm{a}}$ Parameter estimates for favorable (in parentheses for unfavorable) employment opportunities. ${ }^{*} p<.05 .{ }^{* * * *} p<.001$

Moreover, goal disengagement at graduation was associated with an increase in satisfaction with work. The effect sizes were quite substantial. Thus, how young adults dealt with their occupational goals was closely linked to changes in their well-being.

\section{A Note on Mean-Level Changes}

Although not the focus of our analyses, we found interesting, small mean-level changes in occupational motivation and wellbeing. Over time, both occupational goal engagement and goal disengagement decreased. This finding suggests that the first year during the transition into work is indeed a challenge to the motivational system. At graduation, these motivational strategies were more activated and, over time, returned to lower levels. Moreover, over time, satisfaction with work increased, positive affect increased, and depressive symptoms decreased, suggesting that individuals overall became more adjusted to the new life stage. However, purpose in life on average also decreased during the transition-converging with cross-sectional findings that show lower levels of purpose in life with higher age (Ryff \& Keyes, 1995). Reasons for this trend deserve further investigation. Perhaps becoming more disillusioned with increasing age results in a decrease in purpose in life? Importantly, individual differences in intraindividual change were found for all constructs. These findings illustrate the plasticity of motivation (Vohs \& Baumeister, 2008) and well-being (Diener et al., 2006). This does not mean that motivation or well-being is entirely in flux. Yet, change is possible and, as we discuss now, it occurs in systematic ways.

\section{The Big Picture: More Engaged and Happier, More Disengaged and Unhappier}

As predicted, increases in occupational goal engagement were associated with increases in numerous aspects of well-being (i.e., satisfaction with life, positive affect, positive relations with others, and purpose in life). In contrast, as predicted, increases in occupational goal disengagement were associated with decreases in numerous aspects of well-being (i.e., positive relations with others; purpose in life; and, when employment opportunities were favor- able, positive affect). Moreover, disengagement from occupational goals at graduation was associated with a decrease in satisfaction with partnership. Most findings generalized across the different majors that were associated with more or less favorable employment opportunities, with one important exception noted later.

Thus, engaging with occupational goals was broadly adaptive, and disengaging from occupational goals was broadly maladaptive, converging with our hypotheses and predictions by the motivational theory of life-span development (MTD; Heckhausen et al., 2010). Occupational goals are on time during the transition into work-in contrast, for example, to the transition into retirement, where MTD's congruence principle would predict disengagement to be adaptive. We found mostly correlated changes, suggesting a bidirectional interplay between motivation and well-being during the transition into work. Thus, not only does motivation predict well-being, as shown by many previous studies (e.g., Messersmith \& Schulenberg, 2010; Salmela-Aro, 2009; Skaletz \& SeiffgeKrenke, 2010; Wiese et al., 2002), but well-being in turn can also predict motivation (e.g., Haase, Poulin, \& Heckhausen, 2011). Moreover, our findings extend previous research showing that occupational motivation is linked to both subjective and psychological well-being and thus not only to feelings of satisfaction or happiness but also to perceived purpose in life, for example. Furthermore, the present findings did not indicate any workfamily conflict as we had speculated. On the contrary, the findings supported a work-family enrichment perspective (Greenhaus \& Powell, 2006), which posits that experiences in one domain (i.e., work) can improve well-being in the other domain (i.e., partnership/family) through instrumental and affective pathways. In the present study, there was evidence for positive spillover effects from the occupational to the partnership/family domain. We also found a reverse positive spillover effect in that higher satisfaction with partnership at graduation was associated with an increase in occupational goal engagement. In sum, these findings underscore the myriad of well-being benefits associated with being on time during the transition into work in terms of showing high occupational goal engagement and low disengagement. 


\section{The Exceptions: Costs of Goal Engagement and a Benefit of Goal Disengagement}

There were important exceptions to this dynamic, as predicted. Goal engagement had costs, and goal disengagement had a benefit. The association of goal engagement with depressive symptoms varied depending on whether individuals had studied a major associated with favorable or unfavorable employment opportunities. Under favorable employment opportunities, goal engagement and depressive symptoms showed a small positive correlation at graduation, reminiscent of our earlier finding that adolescents who worried more were also more goal engaged (Nagy, Köller, \& Heckhausen, 2005). Yet, as time unfolded, these individuals appeared to profit from their goal engagement and experienced decreases in their depressive symptoms over time (see also Nurmi \& Salmela-Aro, 2002). However, the opposite effect occurred under unfavorable employment opportunities. At graduation, individuals who started with higher goal engagement started with lower depressive symptoms, indicating perhaps that, in this ecology, a relative lack of sadness and fear was initially conducive to goal engagement. However, over time, individuals who had started with higher goal engagement experienced increases in their depressive symptoms, presumably as they experienced failures and setbacks running against the obstacles of an unfavorable labor market. These findings elucidate when the psychological trade-offs of goal engagement (Pomerantz et al., 2000) are most likely to appear-in contexts with unfavorable opportunities for goal attainment. In addition, goal engagement at graduation was associated with a decrease in autonomy, the ability to "resist social pressures" (Ryff \& Keyes, 1995, p. 727). Newcomers in the world of work are often at the bottom of the hierarchy, and those who are more goal-engaged may be increasingly less inclined to express critical opinions.

In contrast, goal disengagement had a select benefit, being associated with an increase in satisfaction with one's work situation. This finding shows that, although disengaging from occupational goals is problematic in many ways, individuals who disengaged reaped some benefit. They disengaged, accepted their occupational situation, and subsequently became happier with it. Thus, disengagement was not entirely dysfunctional-but shortsighted considering the reductions in many other aspects of wellbeing (see earlier) and the objective longer term costs of disengagement (e.g., Heckhausen, 2002; Roberts et al., 2006).

Taken together, these findings elucidate why we see individual differences in goal engagement and disengagement, a question that has received little empirical attention (Heckhausen et al., 2010). In a context where high goal engagement and low goal disengagement are broadly adaptive, why do not all individuals show this motivational pattern? Why do some individuals invest little energy and time to pursue their occupational goals? Why are some highly inclined to simply settle for the next best job? Our findings show that these maladaptive motivational strategies may provide benefits for well-being that are, however, selective and presumably short-sighted, reflecting a kind of motivational myopia (cf. Ditto, Pizarro, Epstein, Jacobson, \& MacDonald, 2006). It is important to note here that MTD does not propose well-being as the final criterion of successful development but instead focuses on the optimization of primary control, that is, the potential to bring about change in the world through one's own actions (Heckhausen et al.,
2010). Thus, although goal engagement has some costs and goal disengagement has a benefit for well-being, individuals may be well advised to engage and not to disengage during the transition into work.

\section{Implications for Future Research and Applications}

The present findings have implications for future research and applications. First, the findings emphasize the importance of individual agency for successful development. They show that engaging with occupational goals as on-time goals during the transition into work-and not disengaging from them-is associated with a host of benefits, even regarding aspects of well-being where one could have suspected well-being impairments, such as partnership satisfaction or positive relations with others. Future research may further elucidate other times in the life span when high occupational goal engagement is broadly beneficial—and when inability to disengage from occupational goals may become problematic (e.g., transition to retirement; Heckhausen et al., 2010). In addition, our findings provide insight into why some individuals may opt for overall maladaptive motivational strategies, demonstrating their selective well-being benefits. Future research may study whether maladaptive motivational strategies provide similar selective benefits during other transitions-including those where disengagement would be warranted because opportunities for goal attainment have vanished. For example, do individuals who have difficulties letting go (e.g., of a project gone awry) get applauded because "sticking through" is the social norm? In a more general vein, agency approaches can inform applications (e.g., career counseling, intervention) and have the potential to bridge disciplinary boundaries, for example, to life-course sociology (Diewald \& Mayer, 2009).

Second, the present findings contribute to research on subjective (Diener et al., 2006) and psychological (Ryff \& Keyes, 1995) well-being pointing toward the individual him- or herself as an important source of changes in well-being. The present study examined short-term changes in well-being during the transition into work. Well-being has positive effects on many long-term outcomes, including career success, social relations, and health (e.g., Lyubomirsky et al., 2005). Future research may study how short-term changes in well-being predict these long-term outcomes.

Third, the present study focused on a key transition in young adulthood, the transition into work. Economic circumstances may change (and the economic situation appears to be currently brighter for young adults in Germany), but coming of age and finding one's place in the world of work is likely to be a challenge not only for the participants in the present study but for young adults across different times and countries (Shulman \& Nurmi, 2010). Individual agency becomes particularly important under such conditions of challenge, and this may extend to other lifespan transitions related to work and beyond (e.g., Salmela-Aro et al., 2001), suggesting avenues for future research.

\section{Limitations}

The present study has limitations. The correlated changes in the LGM analyses may raise the question of what came first, changes in motivation or changes in well-being. Scollon and Diener (2006) 
provided an in-depth discussion of this issue. We suggest that the correlated changes resulted from a bidirectional interplay between motivation and well-being over shorter time spans that may be uncovered using methods such as experience-sampling procedures. Moreover, the intercept-slope correlations require a cautionary remark. These processes might have occurred across shorter time spans than across the whole year (reflected in the slope).

Second, some measurement limitations need to be noted. The internal consistency of the goal disengagement scale was low, as in previous studies (cf. Heckhausen et al., 2001). The strategies serving goal disengagement may serve as substitutes for each other (and were assessed by only four items). In view of the high validity, satisfactory test-retest reliabilities, and Spearman-Brown reliabilities, we decided to retain the scale in the analyses. To reduce the burden of data collection, single-item measures were used to assess work and partnership satisfaction (cf. Wanous et al., 1997). Moreover, we used a linear LGM for goal engagement in the bivariate LGM, building on Coffman and Millsap (2006). This decision was supported, as all bivariate LGMs showed satisfactory fit. In a more general vein, we studied exclusively explicit, selfreported motivation (cf. Bargh, Gollwitzer, \& Oettingen, 2010).

Third, we examined whether the results generalized across four study majors associated with more favorable or more unfavorable employment opportunities. Many other factors shape employment opportunities besides one's study major. One could also argue that the study majors attract different personalities. Yet, a study of 4,000 German students using Holland's theory of vocational personalities showed that students in the four study majors are surprisingly similar (Nagy, 2005).

Finally, the present study followed a convenience sample of German university graduates during their first year after graduation. University graduates are a privileged social group, albeit not sheltered from economic uncertainty (Blossfeld et al., 2005), which may be particularly troublesome after the great educational investment. We should also note that we do not know whether the mean-level changes were indeed due to the transition, as no pretransition data were available. In sum, future research should study other samples varying in educational attainment and in other countries, preferably representative; include pretransition data; use shorter time intervals to uncover bidirectional effects; and/or investigate longer term outcomes.

\section{Conclusion}

Life-span transitions are times of challenge, and the transition into work is a prime example due to the substantial economic uncertainties that affect young adults across the globe (Blossfeld et al., 2005). The present study showed that how young adults deal with their occupational goals is closely linked to changes in their well-being. Increases in occupational goal engagement are associated with increases in numerous aspects of well-being; increases in goal disengagement are associated with decreases in numerous aspects of well-being during the transition into work. However, even in a situation where occupational goal engagement is on time and highly adaptive, we showed some costs of goal engagement and a benefit of goal disengagement. These findings may elucidate why some individuals may opt for overall maladaptive motivational strategies. They provide selective benefits, but their downsides are far more severe-a case of motivational myopia.

\section{References}

Abele, A. E. (2003). The dynamics of masculine-agentic and femininecommunal traits: Findings from a prospective study. Journal of Personality and Social Psychology, 85, 768-776. doi:10.1037/00223514.85.4.768

Allen, T. D., Herst, D. E. L., Bruck, C. S., \& Sutton, M. (2000). Consequences associated with work-to-family conflict: A review and agenda for future research. Journal of Occupational Health Psychology, 5, 278-308. doi:10.1037/1076-8998.5.2.278

Andresen, E. M., Malmgren, J. A., Carter, W. B., \& Patrick, D. L. (1994). Screening for depression in well older adults: Evaluation of a short form of the CES-D. American Journal of Preventive Medicine, 10, 77-84.

Bargh, J. A., Gollwitzer, P. M., \& Oettingen, G. (2010). Motivation. In S. T. Fiske, D. T. Gilbert \& G. Lindzey (Eds.), Handbook of social psychology (5th ed., Vol. 1, pp. 268-316). Hoboken, NJ: Wiley.

Bauer, I., \& Wrosch, C. (2011). Making up for lost opportunities: The protective role of downward social comparisons for coping with regrets across adulthood. Personality and Social Psychology Bulletin, 37, 215228. doi:10.1177/0146167210393256

Bauer, J. J., \& McAdams, D. P. (2004). Growth goals, maturity, and well-being. Developmental Psychology, 40, 114-127. doi:10.1037/ 0012-1649.40.1.114

Blossfeld, H.-P., Klijzing, E., Mills, M., \& Kurz, K. (2005). Globalization, uncertainty and youth in society: The losers in a globalizing world. New York, NY: Routledge.

Brandtstädter, J. (2009). Goal pursuit and goal adjustment: Self-regulation and intentional self-development in changing developmental contexts. Advances in Life Course Research, 14, 52-62. doi:10.1016/ j.alcr.2009.03.002

Briedis, K. (2007). Übergänge und Erfahrungen nach dem Hochschulabschluss [Transitions and experiences after graduation]. Hannover, Germany: HIS GmbH.

Briedis, K., \& Minks, K.-H. (2007). Generation Praktikum-Mythos oder Massenphänomen? [Generation internship-Myth or mass phenomenon?]. Retrieved from http://www.his.de/pdf/22/generationpraktikum.pdf

Browne, M. W., \& Cudeck, R. (1993). Alternative ways of assessing model fit. In K. A. Bollen \& J. S. Long (Eds.), Testing structural equation models (pp. 136-162). Newbury Park, CA: Sage.

Brunstein, J. C. (1993). Personal goals and subjective well-being: A longitudinal study. Journal of Personality and Social Psychology, 65, 1061-1070. doi:10.1037/0022-3514.65.5.1061

Byrne, B. M., \& Stewart, S. M. (2006). The MACS approach to testing for multigroup invariance of a second-order structure: A walk through the process. Structural Equation Modeling, 13, 287-321. doi:10.1207/ s15328007sem1302_7

Carver, C. S., \& Scheier, M. F. (1998). On the self-regulation of behavior. New York, NY: Cambridge University Press.

Coffman, D. L., \& Millsap, R. E. (2006). Evaluating latent growth curve models using individual fit statistics. Structural Equation Modeling, 13, 1-27. doi:10.1207/s15328007sem1301_1

Csikszentmihalyi, M. (2000). Beyond boredom and anxiety. San Francisco, CA: Jossey-Bass.

Deci, E. L., \& Ryan, R. M. (Eds.). (2002). Handbook of self-determination research. Rochester, NY: University of Rochester Press.

Diener, E. (2000). Subjective well-being: The science of happiness and a proposal for a national index. American Psychologist, 55, 34-43. doi: 10.1037/0003-066X.55.1.34

Diener, E., Emmons, R. A., Larsen, R. J., \& Griffin, S. (1985). The Satisfaction With Life Scale. Journal of Personality Assessment, 49, 71-75. doi:10.1207/s15327752jpa4901_13

Diener, E., Lucas, R. E., \& Scollon, C. N. (2006). Beyond the hedonic treadmill: Revising the adaptation theory of well-being. American Psychologist, 61, 305-314. doi:10.1037/0003-066X.61.4.305

Diewald, M., \& Mayer, K. U. (2009). The sociology of the life course and 
life span psychology: Integrated paradigm or complementing pathways? Advances in Life Course Research, 14, 5-14. doi:10.1016/ j.alcr.2009.03.001

Ditto, P. H., Pizarro, D. A., Epstein, E. B., Jacobson, J. A., \& MacDonald, T. K. (2006). Visceral influences on risk-taking behavior. Journal of Behavioral Decision Making, 19, 99-113. doi:10.1002/bdm.520

Duncan, T. E., \& Duncan, S. C. (2004). An introduction to latent growth curve modeling. Behavior Therapy, 35, 333-363. doi:10.1016/S00057894(04)80042-X

Eccles, J. S., \& Wigfield, A. (2002). Motivational beliefs, values, and goals. Annual Review of Psychology, 53, 109-132. doi:10.1146/ annurev.psych.53.100901.135153

Fredrickson, B. L. (2001). The role of positive emotions in positive psychology: The broaden-and-build theory of positive emotions. American Psychologist, 56, 218-226. doi:10.1037/0003-066X.56.3.218

Freund, A. M., Nikitin, J., \& Ritter, J. O. (2009). Psychological consequences of longevity: The increasing importance of self-regulation in old age. Human Development, 52, 1-37. doi:10.1159/000189213

Galambos, N. L., \& Krahn, H. J. (2008). Depression and anger trajectories during the transition to adulthood. Journal of Marriage and Family, 70, 15-27. doi:10.1111/j.1741-3737.2007.00458.x

Gosling, S. D., Vazire, S., Srivastava, S., \& John, O. P. (2004). Should we trust web-based studies? A comparative analysis of six preconceptions about Internet questionnaires. American Psychologist, 59, 93-104. doi: 10.1037/0003-066X.59.2.93

Greenhaus, J. H., \& Beutell, N. J. (1985). Sources of conflict between work and family roles. Academy of Management Review, 10, 76-88. doi: $10.2307 / 258214$

Greenhaus, J. H., \& Powell, G. N. (2006). When work and family are allies: A theory of work-family enrichment. Academy of Management Review, 31, 72-92. doi:10.2307/20159186

Haase, C. M. (2007). Agency and adaptive development during the transition from university to work: A longitudinal study (Doctoral dissertation, University of Jena). Retrieved from http://www.db-thueringen.de/ servlets/DocumentServlet?id $=10303$

Haase, C. M., Heckhausen, J., \& Köller, O. (2008). Goal engagement during the school-to-work transition: Beneficial for all, particularly for girls. Journal of Research on Adolescence, 18, 671-698. doi:10.1111/ j.1532-7795.2008.00576.x

Haase, C. M., Poulin, M. J., \& Heckhausen, J. (2011). Happiness as a motivator: Positive affect predicts primary control striving for career and educational goals. Manuscript submitted for publication.

Hall, N. C., Chipperfield, J. G., Heckhausen, J., \& Perry, R. P. (2010). Control striving in older adults with serious health problems: A 9-year longitudinal study of survival, health, and well-being. Psychology and Aging, 25, 432-445. doi:10.1037/a0019278

Heckhausen, J. (2002). Transition from school to work: Societal opportunities and the potential for individual agency. Journal of Vocational Behavior, 60, 173-177. doi:10.1006/jvbe.2001.1862

Heckhausen, J., Schulz, R., \& Wrosch, C. (1998). Developmental regulation in adulthood: Optimization in Primary and Secondary Control-A multiscale questionnaire (OPS-Scales) (Unpublished tech. rep.). Berlin, Germany: Max Planck Institute for Human Development and Education.

Heckhausen, J., Wrosch, C., \& Fleeson, W. (2001). Developmental regulation before and after a developmental deadline: The sample case of "biological clock" for childbearing. Psychology and Aging, 16, 400413. doi: $10.1037 / 0882-7974.16 .3 .400$

Heckhausen, J., Wrosch, C., \& Schulz, R. (2010). A motivational theory of life-span development. Psychological Review, 117, 32-60. doi:10.1037/ a0017668

Hox, J. (2002). Multilevel analysis techniques and applications. Mahwah, NJ: Erlbaum.

Kahneman, D., Diener, E., \& Schwarz, N. (Eds.). (1999). Well-being: The foundations of hedonic psychology. New York, NY: Russell Sage Foundation.

Klinger, E. (1975). Consequences of commitment to and disengagement from incentives. Psychological Review, 82, 1-25. doi:10.1037/h0076171

Lerner, R. M., \& Busch-Rossnagel, N. (Eds.). (1981). Individuals as producers of their development: A life-span perspective. New York, NY: Academic Press.

Little, B. R. (1983). Personal projects: A rationale and method for investigation. Environment and Behavior, 15, 273-309. doi:10.1177/ 0013916583153002

Lucas, R. E., Diener, E., \& Suh, E. (1996). Discriminant validity of well-being measures. Journal of Personality and Social Psychology, 71, 616-628. doi:10.1037/0022-3514.71.3.616

Lyubomirsky, S., King, L., \& Diener, E. (2005). The benefits of frequent positive affect: Does happiness lead to success? Psychological Bulletin, 131, 803-855. doi:10.1037/0033-2909.131.6.803

Maier, G. W., \& Brunstein, J. C. (2001). The role of personal work goals in newcomers' job satisfaction and organizational commitment: A longitudinal analysis. Journal of Applied Psychology, 86, 1034-1042. doi: 10.1037/0021-9010.86.5.1034

Marsh, H. W., Hau, K.-T., \& Wen, Z. (2004). In search of golden rules: Comment on hypothesis-testing approaches to setting cutoff values for fit indexes and dangers in overgeneralizing $\mathrm{Hu}$ and Bentler's (1999) findings. Structural Equation Modeling, 11, 320-341. doi:10.1207/ s15328007sem1103_2

McArdle, J. J., \& Epstein, D. (1987). Latent growth curves within developmental structural equation models. Child Development, 58, 110-133. doi: $10.2307 / 1130295$

Messersmith, E. E., \& Schulenberg, J. E. (2010). Goal attainment, goal striving, and well-being during the transition to adulthood: A ten-year U.S. national longitudinal study. New Directions for Child and Adolescent Development, 2010(130), 27-40. doi:10.1002/cd.279

Morling, B., \& Evered, S. (2006). Secondary control reviewed and defined. Psychological Bulletin, 132, 269-296. doi:10.1037/0033-2909 .132 .2 .269

Moskowitz, J. T., Epel, E. S., \& Acree, M. (2008). Positive affect uniquely predicts lower risk of mortality in people with diabetes. Health Psychology, 27, S73-S82. doi:10.1037/0278-6133.27.1.S73

Muthén, L. K., \& Muthén, B. O. (1998-2007). Mplus user's guide (5th ed.). Los Angeles, CA: Muthén \& Muthén.

Nagy, G. (2005). Berufliche Interessen, kognitive und fachgebundene Kompetenzen: Ihre Bedeutung für die Studienfachwahl und die Bewährung im Studium [Vocational interests, cognitive, and scholastic abilities: Their role in choice of major and success at university] (Doctoral dissertation, Free University Berlin). Retrieved from http:// www.diss.fu-berlin.de/diss/receive/FUDISS_thesis_000000002714

Nagy, G., Köller, O., \& Heckhausen, J. (2005). Der Übergang von der Schule in die berufliche Erstausbildung: Wer die Sorgen scheut, wird von ihnen ereilt [The transition from school to vocational education: Avoiding worry does not pay]. Zeitschrift für Entwicklungspsychologie und Pädagogische Psychologie, 37, 156-167. doi:10.1026/00498637.37.3.156

Nosek, B. A., Banaji, M. R., \& Greenwald, A. G. (2002). E-research: Ethics, security, design, and control in psychological research on the Internet. Journal of Social Issues, 58, 161-176. doi:10.1111/15404560.00254

Nurmi, J.-E., \& Salmela-Aro, K. (2002). Goal construction, reconstruction and depressive symptoms in a life-span context: The transition from school to work. Journal of Personality, 70, 385-420. doi:10.1111/14676494.05009

Nurmi, J.-E., \& Salmela-Aro, K. (2006). What works makes you happy: The role of personal goals in life-span development. In M. Csikszentmihalyi \& I. S. Csikszentmihalyi (Eds.), A life worth living: Contribu- 
tions to positive psychology (pp. 182-199). New York, NY: Oxford University Press.

Nurmi, J.-E., Salmela-Aro, K., \& Koivisto, P. (2002). Goal importance and related achievement beliefs and emotions during the transition from vocational school to work: Antecedents and consequences. Journal of Vocational Behavior, 60, 241-261. doi:10.1006/jvbe.2001.1866

Pomerantz, E. M., Saxon, J. L., \& Oishi, S. (2000). The psychological trade-offs of goal investment. Journal of Personality and Social Psychology, 79, 617-630. doi:10.1037/0022-3514.79.4.617

Pressman, S. D., \& Cohen, S. (2005). Does positive affect influence health? Psychological Bulletin, 131, 925-971. doi:10.1037/00332909.131.6.925

Roberts, B. W., Walton, K., Bogg, T., \& Caspi, A. (2006). De-investment in work and non-normative personality trait change in young adulthood. European Journal of Personality, 20, 461-474. doi:10.1002/per.607

Ryff, C. D., \& Keyes, C. L. M. (1995). The structure of psychological well-being revisited. Journal of Personality and Social Psychology, 69, 719-727. doi:10.1037/0022-3514.69.4.719

Salmela-Aro, K. (2009). Personal goals and well-being during critical life transitions: The four C's-Channelling, choice, co-agency and compensation. Advances in Life Course Research, 14, 63-73. doi:10.1016/ j.alcr.2009.03.003

Salmela-Aro, K., Nurmi, J.-E., Saisto, T., \& Halmesmäki, E. (2001). Goal reconstruction and depressive symptoms during the transition to motherhood: Evidence from two cross-lagged longitudinal studies. Journal of Personality and Social Psychology, 81, 1144-1159. doi:10.1037/00223514.81.6.1144

Schoon, I., \& Silbereisen, R. K. (Eds.). (2009). Transitions from school to work: Globalization, individualization, and patterns of diversity. New York, NY: Cambridge University Press. doi:10.1017/ CBO9780511605369

Schulenberg, J. E., Bryant, A. L., \& O'Malley, P. M. (2004). Taking hold of some kind of life: How developmental tasks relate to trajectories of well-being during the transition to adulthood. Development and Psychopathology, 16, 1119-1140. doi:10.1017/S0954579404040167

Schulz, R., \& Heckhausen, J. (1998). Emotion and control: A life-span perspective. In K. W. Schaie \& M. P. Lawton (Eds.), Annual Review of Gerontology and Geriatrics: Vol. 17. Focus on emotion and adult development (pp. 185-205). New York, NY: Springer.
Scollon, C. N., \& Diener, E. (2006). Love, work, and changes in extraversion and neuroticism over time. Journal of Personality and Social Psychology, 91, 1152-1165. doi:10.1037/0022-3514.91.6.1152

Shulman, S., \& Nurmi, J. E. (2010). Understanding emerging adulthood from a goal-setting perspective. New Directions for Child and Adolescent Development, 2010(130), 1-11.

Skaletz, C., \& Seiffge-Krenke, I. (2010). Models of developmental regulation in emerging adulthood and links to symptomatology. New Directions for Child and Adolescent Development, 2010(130), 71-82. doi: $10.1002 / \mathrm{cd} .282$

Tomasik, M. J., Hardy, S., Haase, C. M., \& Heckhausen, J. (2009). Adaptive adjustment of vocational aspirations among German youths during the transition from school to work. Journal of Vocational Behavior, 74, 38-46. doi:10.1016/j.jvb.2008.10.003

Vohs, K. D., \& Baumeister, R. R. (2008). Can satisfaction reinforce wanting? A new theory about long-term changes in strength of motivation. In J. Y. Shah \& W. L. Gardner (Eds.), Handbook of motivation science (pp. 373-389). New York, NY: Guilford Press.

Wanous, J. P., Reichers, A. E., \& Hudy, M. J. (1997). Overall job satisfaction: How good are single-item measures? Journal of Applied Psychology, 82, 247-252. doi:10.1037/0021-9010.82.2.247

Wiese, B. S., Freund, A. M., \& Baltes, P. B. (2002). Subjective career success and emotional well-being: Longitudinal predictive power of selection, optimization and compensation. Journal of Vocational Behavior, 60, 321-335. doi:10.1006/jvbe.2001.1835

Wrosch, C., \& Miller, G. E. (2009). Depressive symptoms can be useful Self-regulatory and emotional benefits of dysphoric mood in adolescence. Journal of Personality and Social Psychology, 96, 1181-1190. doi:10.1037/a0015172

Wrosch, C., Scheier, M. F., Carver, C. S., \& Schulz, R. (2003). The importance of goal disengagement in adaptive self-regulation: When giving up is beneficial. Self and Identity, 2, 1-20. doi:10.1080/ 15298860309021

Received January 29, 2011

Revision received August 23, 2011

Accepted October 3, 2011 